Review

\title{
Physical Activity's Impact on Quality of Life in Older Adults with Dementia: A Systematic Review
}

\author{
Tamuyen P. Do ${ }^{1}$, Eileen B. O’Keefe ${ }^{1}$, Nicole L. Spartano ${ }^{2,}{ }^{*}$
}

1. Department of Health Sciences, Boston University, Boston MA 02215; E-Mails: tamuyend@bu.edu; ebokeefe@bu.edu

2. Section of Endocrinology, Diabetes, Nutrition \& Weight Management, Boston University School of Medicine, Boston MA 02118; E-Mail: spartano@bu.edu

* Correspondence: Nicole L. Spartano; E-Mail: spartano@bu.edu

Academic Editor: José Ma Cancela Carral

Special Issue: Physical Activity and Older Adults. Intervention Programs

\section{OBM Geriatrics}

2020, volume 4, issue 3

doi:10.21926/obm.geriatr.2003133
Received: June 04, 2020

Accepted: September 17, 2020

Published: September 23, 2020

\begin{abstract}
Individuals with dementia frequently report poor quality of life ( $Q O L)$, which declines as their disease progresses. Some evidence suggests that physical activity may help maintain cognitive function in older age, but it is unclear whether physical activity affects quality of life in older adults with dementia. The purpose of this review paper is to explore whether and how physical activity impacts QOL in patients with diagnosed dementia in different residential settings. To conduct this systematic review, the following search terms were inputted into the search bars of three databases:(dementia OR Alzheimer) AND (walking OR physical activity OR exercise OR fitness) AND (community OR nursing home OR independent living OR green care) AND (Quality of Life). A total of ten articles met the study inclusion criteria. Several studies reported a positive correlation between physical activity intervention programs and $\mathrm{QOL}$ outcome measures, pertaining to socialization and positive emotions, and an increase in physical endurance capacity among program participants. However, most results were not statistically significant. We conclude that more large studies need to be conducted in order to
\end{abstract}

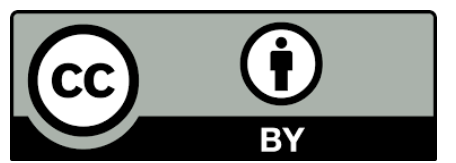

(C) 2020 by the author. This is an open access article distributed under the conditions of the Creative Commons by Attribution License, which permits unrestricted use, distribution, and reproduction in any medium or format, provided the original work is correctly cited. 
establish whether there is a significant positive dose-response relationship between physical activity intervention programs and QOL measures among individuals with diagnosed dementia.

\section{Keywords}

Dementia; Alzheimer's disease; physical activity; quality of life; nursing home; community dwelling

\section{Introduction}

The current prevalence of Alzheimer's disease in the United States is 5.8 million individuals [1]. Of these, an estimated 5.6 million are aged 65 years or older. This number is expected to continue to rise in the next decades due to the increasing number of older individuals among the U.S. population. Studies estimate that by 2025 , there will be a $27 \%$ increase in the number of individuals older than 65 living in the United States with Alzheimer's disease [1].

The number of individuals living with Alzheimer's disease is not expected to decline in the near future, therefore, it is important to consider its overall costs on our healthcare system. An estimated $\$ 290$ billion was spent on dementia care in long-term care and hospice in 2019 alone. Government spending through Medicare and Medicaid covered approximately $67 \%$ of the total health care cost of dementia. Out of pocket payments, with its direct impact on family finances, make up to an estimated $22 \%$ [2].

About $70 \%$ of individuals older than 65 living with dementia reside in the community, a dramatic difference from the $98 \%$ of those not diagnosed with dementia [2]. Many of the dementia diagnosed individuals receive some form of paid care. From 2017 to 2018, the average cost of assisted living ranged from $\$ 45,000$ to $\$ 48,000$ per year and nursing home care ranged from $\$ 85,775$ to $\$ 89,297$ a year $[3,4]$. There is no public program, aside from Medicaid, that will pay for long term nursing home care [2].

Actively managing dementia has been shown to lead to an improvement in quality of life (QOL), including participation in meaningful activities and opportunities to socialize with other dementia diagnosed patients [5]. Additionally, studies suggest that physical activity may improve cognitive function for dementia patients $[6,7]$. The purpose of our review is to examine whether physical activity impacts QOL in patients diagnosed with dementia, and also to explore whether the residential setting where these individuals live (nursing home or community-dwelling) play a role in the relationship between physical activity and QOL.

\section{Materials and Methods}

\subsection{Methods}

We input the following search terms into the PubMed, EMBASE, EBSCO (PyschInfo, Ageline, and CINAHL) search bars: (dementia OR Alzheimer) AND (walking OR physical activity OR exercise OR fitness) AND (community OR nursing home OR independent living OR green care) AND (Quality of Life). This search was conducted in September 2018 and contains articles from the year 2000 to the month the search was conducted. 
The PubMed search resulted in 526 peer reviewed articles. Applying study criteria, the articles were then reviewed for relevance to our study. Articles that did not mention dementia, interventions involving physical activity, or no mention of the association of physical activity with QOL in dementia diagnosed patients were excluded from our study. From the PubMed search, seven articles were retained for our systematic review.

Our EBSCO search, in which we gathered articles from PsychInfo, Ageline and CINAHL yielded 243 articles. We added filters in which we selected results for which our search terms were present in the Abstract portion of the article. We also added filters for the articles to be peer reviewed, journal articles, and in English. There were 120 articles excluded since they were duplicates from PubMed and Embase. Of the remaining 123 articles, 122 were excluded due to the same criteria that was used with the PubMed articles. Zero articles met the criteria to the be included.

In EMBASE, we had a search result of 384 articles. We had our filters set to only search for our key terms in the title, Abstract, and author keywords portions of the journal articles. 17 of the articles were excluded since they were duplicates. Of the 367 articles that remained, three met our criteria to be included in our systematic review. Figure 1 provides a visual of our reasons for exclusion.

A total of ten articles were included in our systematic review.

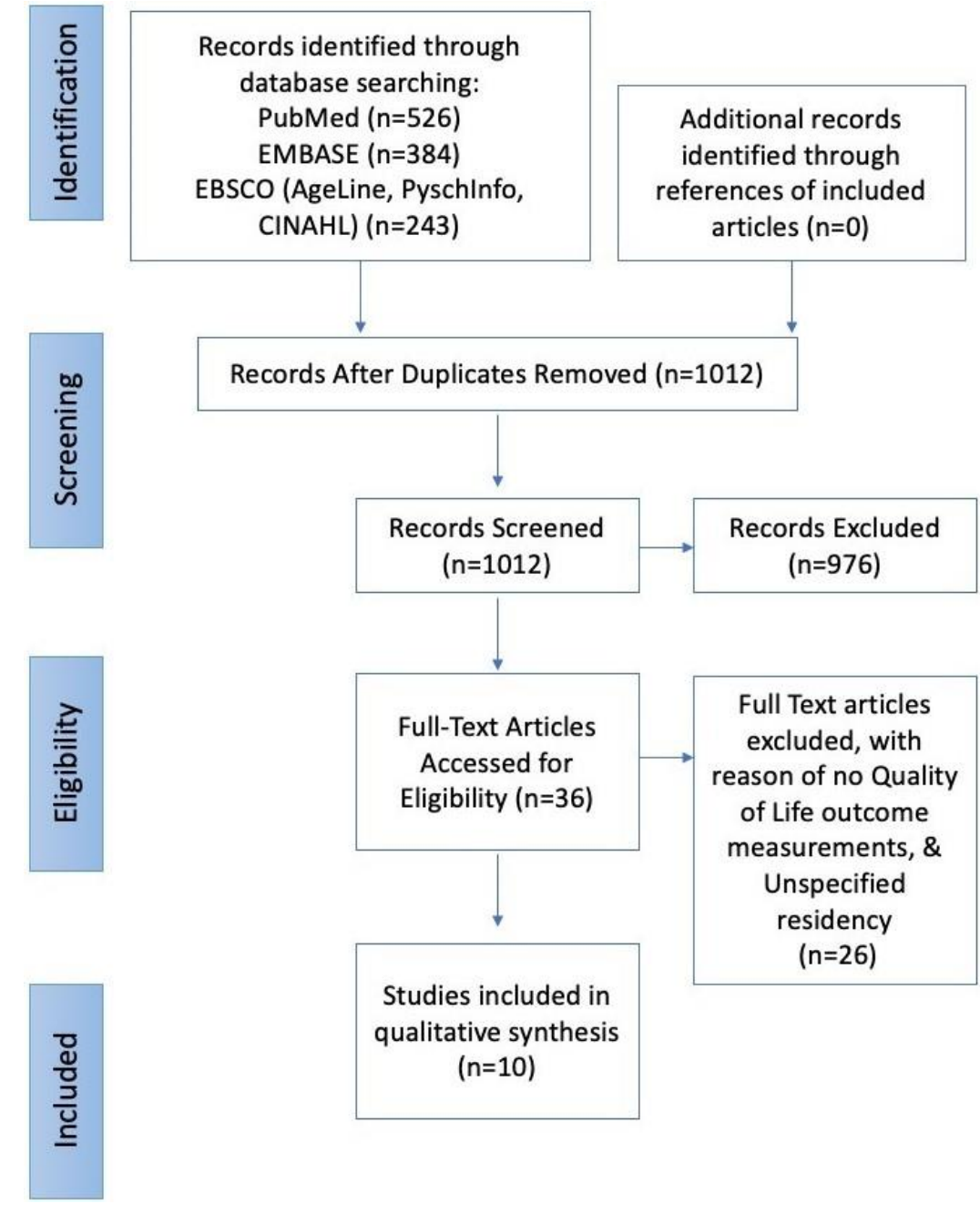

Figure 1 Database Search History with Exclusion Criteria Outlined. 


\subsection{Inclusion Criteria}

Studies included in our systematic review were required to have examined the correlation between physical activity and the QOL of individuals living with dementia as one of their main outcomes, there needed to be a QOL measurement scale present in the study with both baseline and end of study measurements. The study needed to explicitly state whether their study subjects lived in nursing homes or were community dwellers.

\subsection{Exclusion Criteria}

Studies that were not examining dementia, physical activity, QOL, or the experiences of the individual living with dementia were excluded from this systematic review. Additionally, due to our interest in study results, uncompleted studies were excluded.

\subsection{Quality Assessment}

The Jadad Scale was used to evaluate the quality of each of the randomized controlled trials. Items on the scale are randomization, blinding, and whether or not the study accounts for withdrawals and dropouts (Table 1). The scale is rated from zero to five with a score of five being a study of high quality [8].

For non- randomized studies, we used the Methodological Index for Non-Randomized Studies (MINORS) instrument to assess the quality of each study [9] (Table 2).

Table 1 Quality Assessment for Randomized Controlled Trials using the Jadad Scale [8].

\begin{tabular}{|c|c|c|c|c|c|c|}
\hline Item & $\begin{array}{l}\text { Lamb } \\
\text { et al. [10] }\end{array}$ & $\begin{array}{l}\text { Ballard } \\
\text { et al. [11] }\end{array}$ & $\begin{array}{l}\text { Henskens } \\
\text { et al. [12] }\end{array}$ & $\begin{array}{l}\text { Hoffmann } \\
\text { et al. [13] }\end{array}$ & $\begin{array}{l}\text { Telenuis } \\
\text { et al. [14] }\end{array}$ & $\begin{array}{l}\text { Tanaka } \\
\text { et al. [15] }\end{array}$ \\
\hline $\begin{array}{l}\text { Randomizatio } \\
\text { n Mentioned }\end{array}$ & 1 & 1 & 1 & 1 & 1 & 1 \\
\hline $\begin{array}{l}\text { Randomizatio } \\
\text { n Appropriate }\end{array}$ & 0 & 1 & 1 & 1 & 1 & 1 \\
\hline $\begin{array}{l}\text { Blinding } \\
\text { Mentioned }\end{array}$ & 0 & 1 & 1 & 1 & 1 & 1 \\
\hline $\begin{array}{l}\text { Blinding } \\
\text { Appropriate }\end{array}$ & 0 & -1 & -1 & -1 & -1 & -1 \\
\hline $\begin{array}{l}\text { Withdrawals } \\
\text { and Dropouts } \\
\text { Mentioned }\end{array}$ & 1 & 1 & 1 & 1 & 1 & 1 \\
\hline Total & 2 & 3 & 3 & 3 & 3 & 3 \\
\hline
\end{tabular}


Table 2 Quality Assessment for Non-Randomized Trials using the MINORS.

\begin{tabular}{|c|c|c|c|c|}
\hline MINORS [9] & $\begin{array}{l}\text { La Rue } \\
\text { et al. }\end{array}$ & $\begin{array}{l}\text { Henskens } \\
\text { et al. }\end{array}$ & Taylor et al. & Olsen et al. \\
\hline Clearly stated aim & 1 & 1 & 1 & 1 \\
\hline Inclusion of consecutive patients & 0 & 1 & 0 & 1 \\
\hline Prospective collection data & 1 & 1 & 1 & 0 \\
\hline $\begin{array}{l}\text { Endpoints appropriate to the aim } \\
\text { of the study }\end{array}$ & 1 & 1 & 1 & 1 \\
\hline $\begin{array}{l}\text { Unbiased assessment of the study } \\
\text { endpoint }\end{array}$ & 0 & 0 & 0 & 0 \\
\hline $\begin{array}{l}\text { Follow-up period appropriate to } \\
\text { the aim of the study }\end{array}$ & 1 & 1 & 1 & 0 \\
\hline Loss to follow up less than $5 \%$ & 0 & 0 & 0 & 0 \\
\hline $\begin{array}{l}\text { Prospective calculation of the } \\
\text { study size }\end{array}$ & 0 & 0 & 0 & 0 \\
\hline An adequate control group & N/A & 1 & 0 & N/A \\
\hline Contemporary groups & $\mathrm{N} / \mathrm{A}$ & 1 & 0 & N/A \\
\hline Baseline equivalence of groups & $\mathrm{N} / \mathrm{A}$ & 0 & 0 & N/A \\
\hline Adequate statistical analyses & $\mathrm{N} / \mathrm{A}$ & 1 & 1 & $\mathrm{~N} / \mathrm{A}$ \\
\hline Total & 4 & 8 & 5 & 3 \\
\hline
\end{tabular}

\subsection{QOL Scales}

There are several scales used to assess QOL in research. Table 3 lists the QOL scales utilized specifically in the studies included in this review alongside the number of items measured, subscales and scoring for each QOL scale. The number of items measured range from five to 37 . While the range of items vary, the topics covered in the scales are similar. The QUALIDEM, Quality of Life in Dementia (QOL-D), and DEMQOL-PROXY scales each have two topics that ask specifically about "positive affect/emotion" and "negative affect/emotion" [16-18, 20]. The SF-36 HRQL, Qualidem, and QUALID explicitly address social interaction [16,17, 19, 21]. Additionally, the QUALID and Qualidem were administered by caregivers who work closely with the subjects observed [10-12]. The QUALID, Qualidem, and DEMQOL-PROXY state in their studies that they use a Likert Rating Scale for their scale scoring $[16,17,20,22]$. 
Table 3 Overview of QOL Scales.

$\begin{array}{lll}\text { SCALE ITEMS SUBSCALES } & \text { SCORING }\end{array}$

Quality of Life in Late Stage Dementia (QUALID) [19]

QUALIDEM $[16,17]$ 37

QOL-AD (Quality of Life in Alzheimer's disease) [22]

European Quality of Life-5 Dimensions (EQ-5D) [23]

Qol-D (Quality of Life in Dementia) [18]

DEMQOL-PROXY (DEMQOL Performed By Caregiver) [24]
Smiles, appears sad, cries, has facial expression of discomfort, appears physically uncomfortable, verbalizations suggest 11 discomfort, irritable or aggressive, enjoys eating, enjoys touching/being touched, The lower the score the better the QOL (11-55) enjoys interacting with others, appears calm and comfortable

Care relationship, positive affect, negative affect, restless tense behavior, positive self- The higher the score the image, social relations, social isolation, better the QOL (0-27) feeling at home, having something to do

Physical health, energy, mood, living 13 situation, memory, family, marriage, friends, self as a whole,

The higher the score the better the QOL (13-52)

The higher the score the better the QOL

Scoring Unspecified attachment with others, spontaneity and activity

Cognition, negative emotion, daily activities, positive emotion, appearance, non- and cross- loaders
The higher the score the better the QOL (31-124) 
Though there are similarities between the scales, there are a few key differences that set these scales apart. The Qualidem is used to examine subjects with mild to severe dementia and is scored by adding the mean scores of the nine subscales together as opposed to the other studies in which the scores of the items are added together $[16,17]$. The QOL-D used in the study for this systematic review was meant for use in evaluating subjects in Japan and is the only scale to include an item pertaining to living situation [22].

\section{Results}

\subsection{Comparison of Study Designs}

Of the ten studies which met the inclusion criteria (see Table 4), six studies were randomized controlled trials, [10-15] two studies were quasi-experimental studies [25, 26], one study was a cohort study [27], and one study was a cross sectional study [28].

Five of the studies observed community dwelling individuals $[10,13,15,25,27]$, four studies observed nursing homes $[10,11,14,26]$, one study compared community dwelling individuals to nursing home residents [28].

The sample sizes for the studies ranged from 33 participants to 494 participants, there were no differences in sample sizes by living situations. The trial length ranged from three months to 20 months. The longest trial time of $\mathbf{2 0}$ months was observing community dwelling participants [25].

Aside from two studies that only examined mild dementia and mild Alzheimer's disease, the other studies observed varying stages of dementia ranging from mild to severe. Mild dementia is defined by the Clinical Dementia Rating (CDR) scale as an individual with moderate memory loss, moderate difficulty with time relationships, moderated difficulty in handling problems, similarities and differences, however, their social judgement is typically maintained, unable to function independently but still engaged, and mild but definite impairment of function at home. Moderate dementia is defined as severe memory loss in that only highly learned material is retained and new material is rapidly lost, severe difficulty with time relationships, severely impaired handling problems, similarities, and differences, at this stage judgement is typically impaired, and only simple chores are preserved. Lastly, the severe stage of dementia is defined by severe memory loss (only fragments remain, oriented to person only, inability to make judgements or solve problems, cannot be taken outside of family home and there is no significant function in home) [29]. 
OBM Geriatrics 2020; 4(3), doi:10.21926/obm.geriatr.2003133

Table 4 Summary characteristics of studies investigating the role of physical activity for promoting QOL in individuals with dementia or mild cognitive impairment.

\begin{tabular}{|c|c|c|c|c|c|c|c|c|}
\hline Authors & Location & $\begin{array}{l}\text { Living } \\
\text { Situation }\end{array}$ & $\begin{array}{l}\text { QOL } \\
\text { Measure }\end{array}$ & $\begin{array}{l}\text { Stage of } \\
\text { AD/Dementia }\end{array}$ & $\mathrm{n}$ & Study Type & $\begin{array}{l}\text { Study } \\
\text { Length }\end{array}$ & Results \\
\hline $\begin{array}{l}\text { La Rue } \\
\text { et al. } \\
{[25]}\end{array}$ & Wisconsin & $\begin{array}{l}\text { Community } \\
\text { Dwelling }\end{array}$ & QOL-AD & $\begin{array}{l}\text { Mild } \\
\text { Dementia }\end{array}$ & 64 & $\begin{array}{l}\text { Quasi-Experimental: volunteer pairs met } \\
2 x / \text { week for exercise, language } \\
\text { engagement, and social } \\
\text { outing/volunteer work, no control group }\end{array}$ & $\begin{array}{l}20 \\
\text { months }\end{array}$ & $\begin{array}{l}\text { No significant change in } \\
\text { QOL were observed }\end{array}$ \\
\hline $\begin{array}{l}\text { Lamb et } \\
\text { al. [10] }\end{array}$ & England & $\begin{array}{l}\text { Community } \\
\text { Dwelling }\end{array}$ & $E Q-5 D$ & $\begin{array}{l}\text { Mild to } \\
\text { Moderate } \\
\text { Dementia }\end{array}$ & 494 & $\begin{array}{l}\text { Randomized Controlled Trial: supervised } \\
\text { group aerobic/resistance exercise } \\
\text { sessions } 2 x / \text { week (plus weekly } \\
\text { unsupervised exercise session at home) } \\
\text { for } 4 \text { months; then } 8 \text { months } \\
\text { unsupervised exercise program. The } \\
\text { control group received usual care. }\end{array}$ & $\begin{array}{l}12 \\
\text { months }\end{array}$ & $\begin{array}{l}\text { Intervention program did } \\
\text { not improve QOL. } \\
\text { Although physical fitness } \\
\text { increased, cognitive } \\
\text { function decreased in } \\
\text { the treatment group } \\
\text { more than control group } \\
\text { over the 12-month study } \\
\text { period. }\end{array}$ \\
\hline $\begin{array}{l}\text { Henskens } \\
\text { et al. [26] }\end{array}$ & Netherlands & $\begin{array}{l}\text { Nursing } \\
\text { Home }\end{array}$ & Qualidem & $\begin{array}{l}\text { Moderate to } \\
\text { Severe } \\
\text { Dementia }\end{array}$ & 141 & $\begin{array}{l}\text { Quasi- Experimental: } 2 \text { nursing homes } \\
\text { were non-randomly assigned as either } \\
\text { the intervention or control (as usual } \\
\text { care). The intervention included training } \\
\text { on physical activity and independence in } \\
\text { everyday activities }\end{array}$ & $\begin{array}{l}12 \\
\text { months }\end{array}$ & $\begin{array}{l}\text { No significant impact on } \\
\text { overall QOL, but there } \\
\text { was an increase in } \\
\text { positive self-image for } \\
\text { those in the intervention } \\
\text { group after 12-month } \\
\text { follow-up. }\end{array}$ \\
\hline
\end{tabular}




$\begin{array}{lllll}\text { Ballard et } & \text { United } & \text { Nursing } & \text { DEMQOL } & \begin{array}{l}\text { Mild to } \\ \text { al. [11] }\end{array} \\ \text { Kingdom } & \text { Home } & \text { - PROXY } & \begin{array}{l}\text { Severe } \\ \text { Dementia }\end{array}\end{array}$

Henskens

et al. [12]
Qualidem

Home
Moderate to Severe
277

Randomized Controlled Trial (4 groups, factorial design): an antipsychotic

(medication) review intervention, an exercise intervention targeting $1 \mathrm{~h} /$ week individualized plan, a social interaction intervention for at least 1-h/week, and person-centered care only (control)

Randomized Controlled Trial (4 groups): aerobic/strength training $3 \mathrm{x} /$ week and activities of daily living training, social activity $3 x /$ week and activities of daily living training, aerobic/strength training and care-as usual, social activity and care-as-usual

Quasi-Experimental: all participants were offered a home based individual tailored exercise program; there was no control group

Randomized Controlled Trial: intervention group enrolled in supervised exercise group $3 x$ a week; control group received treatment as usual
There was significant improvement in QOL for those receiving the social intervention. For the exercise intervention, there was no impact on overall QOL, but improvement in positive emotion

There was no effect of aerobic/strength training on $\mathrm{OL}$, but $\mathrm{ADL}$ training improved QOL

months constructs, including care relationship, positive self-image, and feeling at home

There was no significant change in QOL postintervention

No significant changes in HRQOL for the intervention group versus control. 


\begin{tabular}{|c|c|c|c|}
\hline $\begin{array}{l}\text { Telenuis } \\
\text { et al. [14] }\end{array}$ & $\begin{array}{l}\text { Oslo, } \\
\text { Norway }\end{array}$ & $\begin{array}{l}\text { Nursing } \\
\text { Home }\end{array}$ & QUALID \\
\hline
\end{tabular}

Tanaka et

al. [15] Japan Community Dwelling

Mild to

Severe

Dementia

\section{Community}

Olsen et

al. [28]
Norway
Mild to

QUALID

Severe
Nursing

Home
Randomized Controlled Trial: the intervention was an intensive strength and balance session 2x/week; the control group participated in leisure activities $2 x$ /week (reading, games, music, and conversation)

Randomized Controlled Trial (3 groups): a 1-h group intervention $2 x /$ week, a 20 min personal training intervention $2 x /$ week, and control group receiving usual care

Dementia
193

Cross Sectional
No significant change in QUALID score in intervention versus control, but the 3

months intervention group reported more significant decrease in feelings of apathy compared to controls

QOL scores did not change in the intervention groups compared to the control group

Home Dwelling participants participated in more moderate activity and had higher QOL than nursing home individuals. Physical activity was not significantly associated with QOL after accounting for residence. 


\subsection{QOL Outcome Measure}

Six distinct QOL scales were used in these studies. Two studies used the QUALID scale [14, 28], two studies assessed their QOL outcome using the Qualidem scale [12, 26], two studies used the QOL-AD scale [25, 27], two used the EQ-5D scale [10, 13], one used the QOL-D scale [15], and one used the DEMQOL-PROXY scale [11].

\subsection{Main Findings}

One study found a linkage between physical activity and QOL [28]. The study by Olsen et al. examined dementia patients residing in nursing homes and those living in the community using a cross sectional study design. The authors found that individuals in nursing homes were significantly less active and spent the majority of their time involved in sedentary activities compared to community dwelling individuals, as measured by an actigraphy device. The nursing home dwelling dementia patients reported lower QOL. After performing a regression analysis, the study demonstrated place of residency had a significant role in lower QOL, after controlling for confounding of age, gender, social encounters, use of walking aids, moderate physical activity level, light exposure, and medication. The study further concluded that, when looking at change in QOL over time, residency accounted for $25 \%$ of the change in QOL among subjects with moderate dementia ( $p$-value $=0.039$ ). Community dwelling subjects living with dementia had a mean change in QOL of -0.38 compared to the mean change in QOL of 1.73 in nursing home resident living with dementia. Baseline QUALID Score and institutionalization significantly predicted the change in QUALID after a six months period $(p<0.05)$ [28].

The remaining physical activity intervention studies did not observe significant changes in the QOL of dementia diagnosed patients following the intervention [10-15, 25-27]. There were improvements in QOL scale categories pertaining to positive self-image, apathy, and positive emotion $[11,14,26]$. One study observed that the intervention group scored significantly better compared to the control group on the Qualidem's positive self-image subscale following a 12 month period ( $p$-value < 0.001) [26]. Another study found the difference between the physical activity intervention group and the control group to be borderline statistically significant for apathy ( $p$-value $=0.048$ ) [14]. Ballard et al.'s study found an improvement in positive emotion for the exercise arm of their intervention ( $p$-value $<0.0001$ ). Additionally, in their social intervention there was a significant improvement in QOL $(p$-value $=0.04)$ [11]. All three of these studies observed residents in nursing homes $[11,14,26]$.

\section{Discussion}

One study used in our systematic review identified a positive correlation between participation in intervention programs and QOL outcome measure while other studies reported positive associations with particular aspects of QOL, but the association with total QOL was not significant $[10-13,26]$. It is unclear why the relationship between physical activity and QOL were observed for some studies and not others. Sensitivity analyses from studies may shed some light.

Three studies observing community dwelling subjects demonstrate a possible relationship between physical activity tolerance with the change in QOL $[10,13,25]$. Participants with mild Alzheimer's disease who attended more sessions had higher ratings of overall QOL [13]. A few 
studies also reported that individuals who achieved higher levels of exercise as the intervention progressed, had higher mean change in QOL $[10,25]$. These findings suggest the potential for certain individuals who can handle more intensive exercise benefitting more from a physical activity intervention, particularly for those with mild dementia since two of the three studies only observed patients with mild Alzheimer's or mild dementia [13, 25]. These findings could point future studies in the direction of studying the characteristics of individuals who benefit from exercise interventions to better understand which individuals to target in policy making and program implementation.

From our systematic review, one study suggests a positive relationship between QOL in dementia diagnosed individuals and physical activity [28]. While physical activity does improve some aspects of QOL, there is insufficient evidence that this leads to an improvement in overall QOL $[12,13,15$, 27]. There may be significant improvement in $\mathrm{QOL}$ for participants enrolled in programs that encourage social interactions with interventions that were personalized to include individual interests and life histories [11]. The studies that saw improvement in particular aspects of QOL relating to positive emotions were all studies observing nursing home residents $[11,12,26]$. In future research, it will be important to examine how a multidimensional intervention that incorporates both social interaction and physical activity could significantly improve QOL as opposed to an intervention that solely focuses on physical activity.

Participation in a physical activity intervention led to an increase for particular QOL outcomes, as measured by belonging, feeling more at home, positive self-image, positive effect on QOL, apathy, and agitation [12]. One study observed that performing familiar activities that were representative of their former home life made participants feel more at home [12]. Social interaction in combination with Person Centered Care significantly improved QOL [11]. Observation of the importance of group membership to maintain and promote well-being was reported [15]. Among nursing home residents, physical activity may reduce apathy and agitation [14].

Although our findings demonstrate possible positive implications on QOL from physical activity interventions, the quality of the studies included in our systematic review were weak to moderate. The Jadad scale was applied to our randomized controlled trials, each of the six studies scored a two or a three due to their inability to double blind [8, 10-15]. The MINORS instrument was used for nonrandomized studies, these studies ranged from three to eight $[9,25-28]$. The study with a score of eight was the highest quality study of our included studies [26].

\subsection{Strengths and Limitations}

We did not identify differences in study methods between studies that reported an effect on QOL from those that did not. The study length, QOL measurement scales, and study types varied in both groups of studies. The QOL measurement scales may not be comparable due to the varying number of items and inclusion of different QOL aspects. Additionally, there may be relevant studies not captured in this review since the researchers did not look at overall QOL specifically but aspects of QOL were assessed during the study. Some of these aspects may be more sensitive to individuals living with dementia. In their reported study limitations, several authors drew attention to the reduced generalizability of their interventions to a broader population because some studies included or limited participants based on the severity of dementia and other studies did not differentiate severity of dementia among study subjects $[15,27]$. Another major limitation included lack of control groups in some of the intervention studies. In the majority of the studies, the control 
arm was a group of participants who were receiving the standard level of care, but it is unclear how intervention groups would compare to individuals receiving no care. Several of the studies included a social interaction component that may have additionally impacted the results of the overall QOL since Ballard et al. found that their social interaction intervention group had better overall QOL results than the physical interaction group $[10-12,15,25,26]$. Lastly, in a study examining wellbeing in the elderly population, the authors posed the question of whether or not wellbeing, which is similar to our definition of QOL, is a stable concept and whether the current QOL measures are not sensitive enough to capture minor changes in individual wellbeing [30].

Finally, studies that did not specify the stage of dementia of their participants were more likely to observe some improvement in $\mathrm{QOL}$ as a result of their intervention compared to studies that exclusively examined participants in a particular dementia stage $[10,11,28]$. This finding suggests that more research should be done to specify a subpopulation of individuals living with dementia in which a physical activity intervention would be most beneficial.

A strength of this review is that it highlights the complexity of conducting research among a population of subjects living with a condition that is difficult to define in terms of severity, varying standards of care, and comorbid conditions. It is at times challenging to categorize this population since dementia is such a heterogeneous disease and individuals with dementia frequently have multiple comorbidities [31].

\subsection{Implications}

Alzheimer's disease not only burdens the individuals living with the disease but also their families and caregivers. In terms of disability -adjusted life years (DALYs), the unit for measuring disease burden, Alzheimer's disease ranked sixth on a 2016 list of most burdensome diseases in the United States [2]. This is a six-rank increase from the 1990 list. The increase in disease burden contributes to the urgent need for large randomized controlled studies to examine the role of a range of physical activity interventions on the QOL of individuals living with dementia. Improving QOL can be a factor that contributes to reducing the disease burden on, not only the individual, but also care-giving burden on their families and caregivers.

This systematic review's purpose was to examine if and how physical activity impacts the QOL of dementia diagnosed patients in nursing homes compared to those residing in the community. Results from our review of the literature showed that in some intervention studies in nursing home residents, physical activity led to improvements in some aspects of QOL, though total QOL was not significantly improved overall. Nursing homes may be promising sites for physical activity program implementation in individuals with dementia because it could be easier to ensure study adherence $[11,12,26]$.

In the United States, community dwelling and traditional nursing homes are the primary living situations for individuals living with dementia, but other options of care could be considered. In the Netherlands and Canada, there has been a shift towards a different form of "nursing home" care called "dementia villages." These villages, designed for individuals living with severe dementia, provide individuals with a sense of independence that is different from a traditional nursing home. The center resembles a small town where residents are allowed to roam independently - partaking in activities of their choosing. Meanwhile, hidden cameras and discreet staff ensure the safety of residents. The rationale for creating such a living environment was to provide individuals with the 
feeling of home without risking their safety. Due to the independence and preservation of dignity that these environments support, "dementia villages" may also promote physical activity. The physical activity comes from the residents' ability to attend programs that are of interest and freedom to walk about the village $[32,33]$.

\section{Conclusions}

While few studies proved physical activity has a significant role in overall QOL, there were several studies that demonstrated how an intervention involving physical activity improved aspects of QOL. Overall, these study findings point toward a positive relationship between physical activity and QOL among individuals with dementia. Large controlled trials among both nursing home and comm unity dwelling study participants are needed to provide the evidence base for intervention program development. One study reported evidence that social interaction may be critical to improving QOL in dementia patients, but this line of research was outside the scope of this current review. Study interventions involving physical activity or social interaction alone, and in combination, could help identify optimal program interventions among this growing population.

\section{Author Contributions}

TPD and NLS developed the topic of this review and the search terms. TPD screened abstracts, created tables, and drafted the manuscript. TPD, NLS, and EBO interpreted tables and edited the manuscript.

\section{Competing Interests}

The authors have declared that no competing interests exist.

\section{References}

1. Hebert L, Weuve J, Scherr P, Evans D. Alzheimer disease in the United States (2010-2050) estimated using the 2010 Census. Neurology. 2013; 80: 1778-1783.

2. Alzheimer's Association. 2019 Alzheimer's disease facts and figures. Alzheimers Dement. 2019; 3: 321-387. doi: 10.1016/j.jalz.2019.01.010.

3. Genworth's 15th annual cost of care survey shows continuing rise in long term care costs. New York: Genworth; 2019. Available from: https://newsroom.genworth.com/2018-10-16Genworths-15th-Annual-Cost-of-Care-Survey-Shows-Continuing-Rise-in-Long-Term-Care-Costs.

4. Genworth 2017 annual cost of care survey: Costs continue to rise across all care settings. New York: Genworth; 2017. Available from: http://investor.genworth.com/investors/newsreleases/archive/archive/2017/Genworth-2017-Annual-Cost-of-Care-Survey-Costs-Continueto-Rise-Across-All-Care-Settings/default.aspx.

5. Vickrey B, Mittman B, Connor K, Pearson M, Della Penna R, Ganiats T. The effect of a disease management intervention on quality and outcomes of dementia care: $A$ randomized, controlled trial. Ann Intern Med. 2006; 145: 713-726.

6. Kemoun G, Thibaud M, Roumagne N, Carette P, Albinet C, Toussaint L, et al. Effects of a physical training programme on cognitive function and walking efficiency in elderly persons with dementia. Dement Geriatr Cogn Disord. 2010; 29: 109-114. 
7. Steinberg M, Leoutsakos IS, Podewils LJ, Lyketsos CG. Evaluation of a home-based exercise program in the treatment of Alzheimer's disease: The maximizing independence in dementia (MIND) study. Int J Geriatr Psychiatry. 2009; 24: 680-685.

8. Jadad AR, Moore RA, Carroll D, Jenkinson C, J Reynolds D, Gavaghan DJ, et al. Assessing the quality of reports of randomized clinical trials: Is blinding necessary? Control Clin Trials. 1996; 17: 1-12.

9. Slim K, Nini E, Forestier D, Kwiatkowski F, Panis Y, Chipponi J. Methodological index for nonrandomized studies (Minors): Development and validation of a new instrument. ANZ J Surg. 2003; 73: 712-716.

10. Lamb SE, Sheehan B, Atherton N, Nichols V, Collins H, Mistry D, et al. Dementia and Physical Activity (DAPA) trial of moderate to high intensity exercise training for people with dementia: Randomised controlled trial. BMJ. 2018; 361: k1675. doi: 10.1136/bmj.k1675.

11. Ballard C, Orrell M, Sun Y, Moniz-Cook E, Stafford J, Whitaker R, et al. Impact of antipsychotic review and non-pharmacological intervention on health-related quality of life in people with dementia living in care homes: WHELD-a factorial cluster randomised controlled trial. Int J Geriatr Psychiatry. 2016; 32: 1094-1103.

12. Henskens $M$, Nauta I, Drost $K$, Scherder $E$. The effects of movement stimulation on activities of daily living performance and quality of life in nursing home residents with dementia: $A$ randomized controlled trial. Clin Interv Aging. 2018; 13: 805-817.

13. Hoffmann K, Høgh P, Johannsen P, Beyer N, Vogel A, Vestergaard K, et al. Moderate-to-High intensity physical exercise in patients with Alzheimer's disease: A randomized controlled trial. J Alzheimer's Dis. 2016; 50: 443-453.

14. Telenius EW, Engedal K, Bergland A. Effect of a high-intensity exercise program on physical function and mental health in nursing home residents with dementia: An assessor blinded randomized controlled trial. PLoS One. 2015; 10: e0126102. doi: 10.1371/journal.pone.0126102.

15. Tanaka S, Yamaguchi H, Honda S, Araya K, Sato Y, Nakano H. Comparison between group and personal rehabilitation for dementia in a geriatric health service facility: Single-blinded randomized controlled study. Psychogeriatrics. 2016; 17: 177-185.

16. Ettema TP, Dröes R-M, de Lange J, Mellenbergh GJ, Ribbe MW. QUALIDEM: Development and evaluation of a dementia specific quality of life instrument-validation. Int J Geriatr Psychiatry. 2007; 22: 424-430.

17. Ettema TP, Dröes R-M, de Lange J, Mellenbergh GJ, Ribbe MW. QUALIDEM: Development and evaluation of a dementia specific quality of life instrument. Scalability, reliability and internal structure. Int J Geriatr Psychiatry. 2007; 22: 549-556.

18. Terada S, Ishizu H, Fujisawa Y, Fujita D, Yokota O, Nakashima H, et al. Development and evaluation of a health-related quality of life questionnaire for the elderly with dementia in Japan. Int J Geriatr Psychiatry. 2002; 17: 851-858.

19. Weiner MF, Martin-Cook K, Svetlik DA, Saine K, Foster B, Fontaine CS. The quality of life in latestage dementia (QUALID) scale. J Am Med Dir Assoc. 2000; 1: 114-116.

20. Mulhern B, Rowen D, Brazier J, Smith S, Romeo R, Tait R, et al. Development of DEMQOL-U and DEMQOL-PROXY-U: Generation of preference-based indices from DEMQOL and DEMQOLPROXY for use in economic evaluation. Health Technol Assess. 2013; 17: 1-160.

21. Ware JE. SF-36 health survey update. Spine Phila Pa 1976. 2000: 25: 3130-3139. 
22. Logsdon RP, Gibbons LP, McCurry SP, Teri LP. Assessing quality of life in older adults with cognitive impairment. Psychosom Med. 2002; 64: 510-519.

23. EuroQol. About EQ-5D. https://euroqol.org/eq-5d-instruments/

24. Smith SC, Lamping DL, Banerjee S, Harwood RH, Foley B, Smith P, et al. Development of a new measure of health-related quality of life for people with dementia: DEMQOL. Psychol Med. 2007; 37: 737-746.

25. La Rue A, Felten K, Turkstra L. Intervention of multi-modal activities for older adults with dementia translation to rural communities. Am J Alzheimers Dis Other Demen. 2015; 30: 468477.

26. Henskens M, Nauta IM, Scherder EA, Oosterveld FJ, Vrijkotte S. Implementation and effects of movement-oriented restorative care in a nursing home-a quasi-experimental study. BMC Geriatr. 2017; 17: 243. doi: 10.1186/s12877-017-0642-x.

27. Taylor ME, Lord SR, Brodaty H, Kurrle SE, Hamilton S, Ramsay E, et al. A home-based, carerenhanced exercise program improves balance and falls efficacy in community-dwelling older people with dementia. Int Psychogeriatrics. 2017; 29: 81-91.

28. Olsen C, Pedersen I, Bergland A, Enders-Slegers M, Jøranson N, Calogiuri G, et al. Differences in quality of life in home-dwelling persons and nursing home residents with dementia-a crosssectional study. BMC Geriatr. 2016; 16: 137. doi: 10.1186/s12877-016-0312-4.

29. Morris JC. The clinical dementia rating (CDR): Current version and scoring rules. Neurology. 1993; 43: 2412-2414.

30. Paw CA, de Jong N, Schouten EG, van Staveren WA, Kok FJ. Physical exercise or micronutrient supplementation for the wellbeing of the frail elderly? A randomised controlled trial. Br J Sports Med. 2002; 36: 126-131.

31. Bunn F, Burn AM, Goodman C, Robinson L, Rait G, Nortonet S, et al. Comorbidity and dementia: A mixed-method study on improving health care for people with dementia (CoDem). Heal Serv Deliv Res. 2016; 4: 1-156.

32. New residents settle into "dementia village" in Langley. Toronto: CBC News; 2019. Available from: https://www.cbc.ca/news/canada/british-columbia/dementia-village-langley-1.5267630.

33. Planos J. The dutch village where everyone has dementia. Washington: The Atlantic; 2014. Available from: https://www.theatlantic.com/health/archive/2014/11/the-dutch-villagewhere-everyone-has-dementia/382195/. 
OBM Geriatrics 2020; 4(3), doi:10.21926/obm.geriatr.2003133

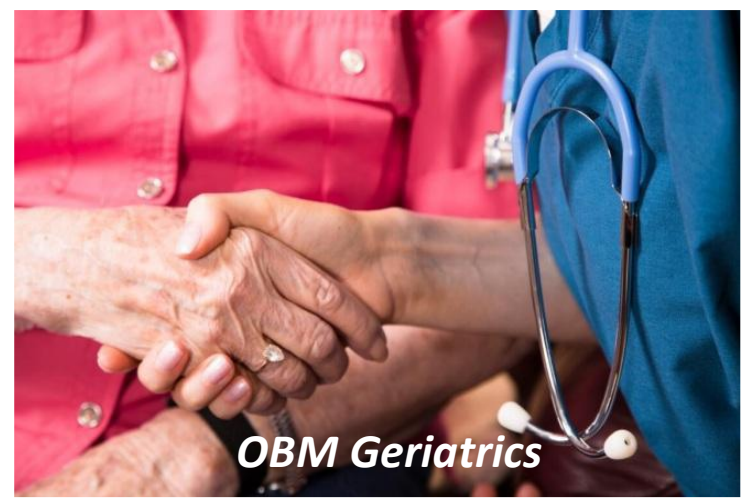

Enjoy OBM Geriatrics by:

1. Submitting a manuscript

2. Joining in volunteer reviewer bank

3. Joining Editorial Board

4. Guest editing a special issue

For more details, please visit:

http://www.lidsen.com/journals/geriatrics 